\title{
Use of hormonal contraceptives and occurrence of pregnancy-related pelvic pain: a prospective cohort study in Norway
}

\author{
Merethe Kumle ${ }^{1}$, Elisabete Weiderpass*2,3,4, Elin Alsaker ${ }^{1}$ and Eiliv Lund ${ }^{1}$
}

Address: ${ }^{1}$ Institute of Community Medicine, University of Troms $ø, 9037$ Troms $ø$, Norway, ${ }^{2}$ Department of Medical Epidemiology, Karolinska Institutet, 17176 Stockholm, Sweden, ${ }^{3}$ Finnish Cancer Registry, Liisankatu 21 B, FIN-00170, Helsinki, Finland and ${ }^{4}$ Cancer Registry of Norway, Montebello, N-0310 Oslo, Norway

Email: Merethe Kumle - merethe.kumle@ism.uit.no; Elisabete Weiderpass* - elisabete.weiderpass@cancer.fi; Elin Alsaker - elin.alsaker@ism.uit.no; Eiliv Lund - eiliv.lund@ism.uit.no

* Corresponding author

Published: 22 June 2004

BMC Pregnancy and Childbirth 2004, 4:II doi:10.1/86/1471-2393-4-1I
Received: 06 February 2004

Accepted: 22 June 2004

This article is available from: http://www.biomedcentral.com/I47/-2393/4/II

(C) 2004 Kumle et al; licensee BioMed Central Ltd. This is an Open Access article: verbatim copying and redistribution of this article are permitted in all media for any purpose, provided this notice is preserved along with the article's original URL.

\begin{abstract}
Background: Pregnancy-related pelvic pain is a common condition, and use of hormonal contraceptives before pregnancy has been proposed as a risk factor. We used data from a subsample of women participating in the "Norwegian Women and Cancer study" (NOWAC) to assess the association between hormonal contraceptive use and pelvic pain in pregnancy.

Methods: From a sub-group of 2078 parous women participating in the NOWAC study, information was collected from a self-instructive four-page questionnaire containing questions about lifestyle and medical conditions. We calculated odds ratios (OR) and $95 \%$ confidence intervals $(\mathrm{Cl})$, using unconditional logistic regression.

Results: In this study, the prevalence of pelvic pain in women was $26.5 \%$ during the first pregnancy and increased with parity. Use of hormonal contraceptives before a woman's first pregnancy was associated with an increased risk of pelvic pain in her first pregnancy $(O R=1.6 ; 95 \%$ confidence interval I.2-2.2). There was no association between use of hormonal contraceptives and pelvic pain in the second or third pregnancy. Occurrence of pelvic pain in a previous pregnancy was the only factor associated with pelvic pain in subsequent pregnancies $(O R=51.1 ; 95 \% \mathrm{Cl} 32.9-79.5$ in the second pregnancy and $\mathrm{OR}=28.3 ; 95 \% \mathrm{Cl} 15.4-53.1$ in the third pregnancy).

Conclusion: Use of hormonal contraceptives was associated with an increased risk of pelvic pain in a woman's first pregnancy. The most important determinant of pelvic pain in the second or third pregnancy was the history of pelvic pain in the preceding pregnancy.
\end{abstract}

\section{Background}

The first documented description of pelvic pain in pregnancy was published by Snelling in the American Journal of Medicine in 1870 [1]. However, it is believed that Hippocrates recognized the disease among pregnant women in Ancient Greece as far back as 400 BC. Pelvic pain in pregnancy is one of the many terms used to describe a collection of typical symptoms [2-5]. Other terms used in scientific literature are: low back pain [6-8], back pain [3,9-11], backache [12] and symphysial pain [10]. In Norway this condition is termed "bekkenløsning". This word incorporates pregnancy-related low back 
pain and pelvic pain. The symptoms vary in strength from discomfort to complete immobilization. Several studies have indicated that pelvic pain in pregnancy is a widespread, and possibly increasing, health problem among women in industrialized countries [7,9,13-15]. The prevalence of pelvic pain in pregnancy varies between $25-50 \%$ in different studies $[7-9,12]$. Several risk factors for this condition have been hypothesized, such as age, parity, education, back pain before pregnancy, type of employment, body size, smoking habits, and use of hormonal contraceptives [2].

We present here results from a study of pelvic pain in pregnancy in relation to hormonal contraceptive use before the first pregnancy and between pregnancies.

\section{Methods \\ Study population}

The "Norwegian Women and Cancer study" (NOWAC) was implemented between 1991 and 1997. A total of 179,388 women from $30-70$ years of age were invited to participate, and 102,443 agreed [16]. All women were sampled randomly from the national population register of Norway. This register records the addresses of all persons alive and residing in the country, and the dates of death or migration to and from Norway since 1960. In this register, each person is identified by a unique 11-digit national registration number. The first six digits encode information on the date of birth, and the last five digits use an algorithm to ensure a unique number, and include information on gender [17]. Health survey questionnaires were mailed to women in batches for convenience. In 1991-2, as part of NOWAC, a four-page questionnaire was mailed to a batch of 4,000 women born between 1943 and 1957 (35-49 years of age). Women who did not return the questionnaire in a few weeks were mailed a reminder with an identical letter of introduction and questionnaire. The questionnaires were returned to the Institute of Community Medicine in Tromsø, Norway.

The questionnaire assessed lifestyle characteristics, reproductive history, including number and duration of each pregnancy, prevalent diseases, and other different medical conditions, including pelvic pain during each pregnancy. We asked about the occurrence of pregnancy-related pelvic pain (Did you suffer from pelvic pain in any of your pregnancies?) and the grade or severity of the symptoms during each of the first three pregnancies (severe disability, problems with walking, painful walking, problems in doing housework, normal physical function level). We used the severity question to classify pelvic pain in the first three pregnancies. Hormonal contraceptives were introduced on the Norwegian market in 1967. Questions about hormonal contraceptive use were summary measures (as ever having used, total estimated overall duration of use, and use before first pregnancy) with detailed questions for each period of use, such as age when use began, brand used, age when use was interrupted, and duration of use. A folder with photos of almost all the 36 hormonal contraceptive brands that have ever been on the Norwegian market was enclosed with the questionnaire to help women to recall use of these drugs.

\section{Data analysis}

From the 4,000 women randomly selected for this substudy we excluded 52 women who had emigrated, were dead at the time the questionnaire was sent, or had a severe mental handicap. Altogether 2,400 women agreed to participate in the study and returned a completed questionnaire, giving a crude response rate of $60.0 \%$ or a corrected response rate of $60.8 \%$. Of these, 2,188 women reported at least one pregnancy lasting six months or more.

We further excluded 35 women due to a lack of information on the use of hormonal contraceptives and 75 women who did not answer the question about pelvic pain. Thus, 2,078 women were included in the final analysis presented here.

We registered twin pregnancies as one pregnancy. We classified hormonal contraceptives in two ways. Firstly, all hormonal contraceptives - regardless of the mode of administration (oral or injectable), and hormonal content (combined estrogen-progestin contraceptives, and medroxyprogesterone acetate only pills or injections) were considered together. Secondly, we classified contraceptives according to the hormonal content as progestinonly contraceptives, and combined estrogen-progestin contraceptives. We classified women as having used hormonal contraceptives before the first pregnancy, before second pregnancy (regardless if the use was only before first pregnancy, both before first pregnancy and between first and second pregnancy, or only between first and second pregnancy) and before third pregnancy (as for the second pregnancy, but also including women using contraceptives between the second and third pregnancies).

The statistical analyses were performed using the SAS statistical package version 8.12. Logistic regression was used for the estimation prevalence of odds ratios (OR) with 95\% confidence intervals (CI). Analyses were done separately for each of the three first pregnancies.

In the multivariate analysis, besides use of hormonal contraceptives before each relevant pregnancy, we included in the models the following co-variables hypothesized to be associated with pregnancy-related pelvic pain: time elapsed since relevant birth, weight of the newborn in each relevant pregnancy and age at menarche. In the 
Table I: Characteristics of the study population $(n=1$ | 63$)$

\begin{tabular}{|c|c|c|c|}
\hline & Study cohort Number (\%) & $\begin{array}{l}\text { Used hormonal contraceptives } \\
\text { before first birth }\end{array}$ & \\
\hline & & $\%$ & $P$ value \\
\hline \multicolumn{4}{|l|}{ Age } \\
\hline $35-36$ years & $320(15.4)$ & 49.1 & \\
\hline $37-38$ years & $273(13.1)$ & 49.5 & \\
\hline $39-40$ years & $276(13.3)$ & 42.4 & \\
\hline $41-42$ years & $296(14.2$ & 27.4 & \\
\hline $43-44$ years & $260(12.5)$ & 20.4 & \\
\hline $45-46$ years & $296(14.2)$ & 15.5 & \\
\hline 4949 years & $357(17.2)$ & 10.9 & $p<0.0001$ \\
\hline \multicolumn{4}{|l|}{ Age at menarche } \\
\hline$<=12$ year & $538(26.4)$ & 30.1 & \\
\hline 13 years & $615(30.2)$ & 35.5 & \\
\hline$>=14$ years & $882(43.3)$ & 26.6 & $P=0.001$ \\
\hline \multicolumn{4}{|l|}{ Age at first birth } \\
\hline$<=20$ years & $503(24.2)$ & 6.4 & \\
\hline $21-25$ years & $961(46.3)$ & 25.6 & \\
\hline$>=26$ years & $614(29.5)$ & 57.0 & $p<=0.0001$ \\
\hline \multicolumn{4}{|c|}{ Weight of newborn child } \\
\hline$-3000 \mathrm{~g}$ & $360(18.0)$ & 31.4 & \\
\hline $3000 \mathrm{I}-3500 \mathrm{~g}$ & $750(37.4)$ & 31.2 & \\
\hline $3501-4000 \mathrm{~g}$ & $617(30.8)$ & 28.4 & \\
\hline$>=400 \mathrm{lg}$ & $276(13.8)$ & 31.9 & $P=0.6$ \\
\hline \multicolumn{4}{|l|}{ Education } \\
\hline 7-9 years & $428(20.9)$ & 12.9 & \\
\hline $10-12$ years & $759(37.2)$ & 24.2 & \\
\hline $13-15$ years & $517(25.3)$ & 39.9 & \\
\hline$>=16$ years & $339(16.6)$ & 51.9 & $p<0.0001$ \\
\hline \multicolumn{4}{|c|}{ Years between menarche and first birth } \\
\hline $0-5$ years & $215(10.6)$ & 5.6 & \\
\hline $6-10$ years & $926(45.5)$ & 17.4 & \\
\hline $11-15$ years & $628(30.9)$ & 43.0 & \\
\hline$>=16$ years & $266(13.1)$ & 64.7 & $P<0.0001$ \\
\hline \multicolumn{4}{|l|}{ Number of births } \\
\hline One & $307(14.8)$ & 46.3 & \\
\hline Two & $1044(50.2)$ & 32.2 & \\
\hline Three & $543(26.1)$ & 23.9 & \\
\hline$>=$ Four & I84(8.9) & 10.9 & $P<0.0001$ \\
\hline \multicolumn{4}{|c|}{ Smoking in the first pregnancy } \\
\hline No & $1396(69.6)$ & 30.5 & \\
\hline Yes & $611(30.4)$ & 30.0 & $p=0.8$ \\
\hline
\end{tabular}

analysis of pelvic pain in the first pregnancy we also included indicator variables for potential risk factors in the multivariate regression models, namely education, height of the mother and smoking habits during the first pregnancy. However, since they did not affect the risk estimates meaningfully, they were excluded in the multivariate analysis of the second and third pregnancies.

For the analysis of the second and third pregnancies we considered the occurrence of pelvic pain in the previous pregnancy as potential determinants of pelvic pain in the following pregnancy.

\section{Results}

\section{Characteristics of the study participants}

Some characteristics of the women included in the study are shown in Table 1. The age distribution in the study population was nearly uniform, while use of hormonal contraceptives before first pregnancy decreased with increasing age at enrolment. Women who reached menarche before age 14 were more likely to have used 
hormonal contraceptives before their first pregnancy than women over 14 years of age at menarche $(p=0.001)$. Age at first birth, years of education, and interval between menarche and first birth were directly associated with hormonal contraceptive use before first pregnancy ( $\mathrm{p}$ values $<$ or $=0.001)$. The inverse was observed with number of births $(p<0.001)$. Use of hormonal contraceptives before first pregnancy was unrelated with weight of the first newborn child $(\mathrm{p}=0.60)$. Nearly one-third of the women smoked during their first pregnancy. The proportion of hormonal contraceptive users before first pregnancy was similar among smokers and non-smokers.

\section{Pelvic pain in pregnancy}

Pregnancy-related pelvic pain - in the first, second or third pregnancy - was reported most often in the youngest women in our study (data not shown). The proportion of women reporting pregnancy-related pelvic pain increased with the number of pregnancies $22.9 \%$ in the first pregnancy, $27.4 \%$ in the second pregnancy and $34.0 \%$ in the third pregnancy). Similar increase in the prevalence of pelvic pain with increasing number of pregnancies was observed in all age groups, irrespective of age at study enrolment (data not shown).

\section{Pelvic pain in the first pregnancy}

Women who reported having used hormonal contraceptives before their first pregnancy reported a higher frequency of pelvic pain in the first pregnancy as compared with non-users $(\mathrm{OR}=1.6 ; 95 \% \mathrm{CI} 1.2-2.1)$ (Table 2). Neither age at menarche, age at first birth, time elapsed since first birth; weight of newborn child, years of education nor smoking during the first pregnancy changed significantly the risk estimated in this analysis (Table 2).

\section{Pelvic pain in the second and third pregnancies}

Use of hormonal contraceptives before second and before third pregnancy was not associated with risk of pregnancy-related pelvic pain in the second or third pregnancy $(\mathrm{OR}=1.0 ; 95 \%$ CI $0.7-1.5$ and $\mathrm{OR}=1.2 ; 95 \% \mathrm{CI} 0.7-1.9$ respectively). The only important determinant of pregnancy-related pelvic pain in the second or third pregnancy was the history of pregnancy-related pelvic pain in the preceding pregnancy $(\mathrm{OR}=57.3 ; 95 \%$ CI $40.5-81.2 \mathrm{in}$ second pregnancy and $\mathrm{OR}=31.2 ; 95 \%$ CI $19.7-49.4$ in third pregnancy) (Table 3 ). Pregnancy-related pelvic pain in the second pregnancy (but not in the first) was a strong predictor of pelvic pain in the third pregnancy (RR 18.0, 95\% CI 8.2-39.6). Women who presented pregnancyrelated pain in the first two pregnancies had an extremely high risk of also suffering from it in the third pregnancy (RR 232, 95\% CI 82-658).

Table 2: Odds ratio (OR) with $95 \%$ confidence intervals $(\mathrm{Cl})$ for pregnancy-related pelvic pain in the first pregnancy

\begin{tabular}{ll}
\hline Characteristic & Pregnancy-related pelvic pain in first pregnancy \\
& OR $(95 \% \mathrm{Cl}) *$ \\
\hline Use of hormonal contraceptives before first birth & \\
No & 1.0 (ref.) \\
Yes & $1.6(1.2-2.1)$ \\
Age at menarche & $1.0($ ref.) \\
$<=12$ years & $0.9(0.7-1.2)$ \\
13 years & $0.8(0.6-1.1)$ \\
$14+$ years & $1.0($ ref. $)$ \\
Age at first birth & $1.2(0.9-1.5)$ \\
$2=20$ years & $0.8(0.5-1.1)$ \\
$21-25$ years & $0.9(0.8-1.0)$ \\
$26+$ years & $1.0(0.95-1.1)$ \\
Time elapsed since first birth (per 3 years)** & $1.0($ ref.) \\
Weight of newborn child (per 500 g) & $1.0(0.7-1.3)$ \\
Years of education & $0.9(0.7-1.3)$ \\
$7-9$ & $1.1(0.7-1.7)$ \\
$10-12$ & 1.0 (ref.) \\
$13-15$ & $0.9(0.7-1.1)$ \\
$16+$ &
\end{tabular}

* All variables are mutually adjusted. Analysis includes women with valid information for listed variables, i.e. 437 women with and I424 women without pregnancy-related pelvic pain during their first pregnancy. ** Years between first birth and enrolment in the study cohort. 
Table 3: Relative risk (RR) with $95 \%$ confidence intervals $(\mathrm{Cl})$ for pregnancy-related pelvic pain in the second and third pregnancies according to history of previous pregnancy (ies)

\begin{tabular}{|c|c|c|}
\hline Characteristic & $\begin{array}{c}\text { Pregnancy-related pelvic pain in second } \\
\text { pregnancy }\end{array}$ & $\begin{array}{c}\text { Pregnancy-related pelvic pain in third } \\
\text { pregnancy }\end{array}$ \\
\hline & $\operatorname{RR}(95 \% \mathrm{Cl})^{*}$ & $\operatorname{RR}(95 \% \mathrm{Cl})^{* *}$ \\
\hline \multicolumn{3}{|l|}{ Pregnancy-related pelvic pain in first pregnancy } \\
\hline No & 1.0 (ref.) & - \\
\hline Yes & $57.3(40.5-81.2)$ & - \\
\hline \multicolumn{3}{|l|}{$\begin{array}{l}\text { Pregnancy-related pelvic pain in at least one of } \\
\text { the first two pregnancies }\end{array}$} \\
\hline No & - & 1.0 (ref.) \\
\hline Yes & - & $31.2(19.7-49.4)$ \\
\hline $\begin{array}{l}\text { Not suffered from Pregnancy-related pelvic } \\
\text { pain in the previous two pregnancies }\end{array}$ & & 1.0 (ref) \\
\hline Pregnancy-related pelvic pain & - & \\
\hline in the first but not in the second pregnancy & - & $1.4(0.5-4.0)$ \\
\hline not in the first but in the second pregnancy & - & $18.0(8.2-39.6)$ \\
\hline both in the first and the second pregnancy & - & $232(82-659)$ \\
\hline
\end{tabular}

Table 4: Odds ratio (OR) with $95 \%$ confidence intervals $(\mathrm{Cl})$ for pregnancy-related pelvic pain in the first pregnancy

\begin{tabular}{|c|c|c|}
\hline Characteristic & $\mathbf{N}$ & $\begin{array}{c}\text { Pregnancy-related pelvic pain in first } \\
\text { pregnancy }\end{array}$ \\
\hline & & OR $(95 \% \mathrm{Cl}) *$ \\
\hline No use & 1290 & I.0 (ref.) \\
\hline \multicolumn{3}{|c|}{$\begin{array}{l}\text { Duration of hormonal contraceptives } \\
\text { before first pregnancy** }\end{array}$} \\
\hline I-29 months & 245 & $1.8(1.3-2.5)$ \\
\hline $30-59$ months & 135 & $1.2(0.8-1.9)$ \\
\hline 60 months or more & 135 & $1.6(1.0-2.5)$ \\
\hline \multicolumn{3}{|c|}{$\begin{array}{l}\text { Type of hormonal contraceptives used } \\
\text { before first pregnancy**** }\end{array}$} \\
\hline Progestin-only contraceptives & 71 & $1.7(0.97-2.8)$ \\
\hline $\begin{array}{l}\text { Combined estrogen-progestin } \\
\text { contraceptives } * * * * *\end{array}$ & 323 & $1.7(1.2-2.3)$ \\
\hline
\end{tabular}

\footnotetext{
* Adjusted for age at menarche, years of education, smoking during first pregnancy, age at first birth, weight of newborn and time since first birth (years between first birth and enrolment in the study cohort). **Analysis includes women with valid information for duration and adjustment variables, i.e. $42 \mathrm{I}$ women with and 1384 without pregnancy related pelvic pain in first pregnancy. ${ }^{* * *}$ Analysis includes women with valid information for brand name and adjustment variables, i.e. 387 women with and 1297 without pregnancy related pelvic pain in first pregnancy. **** Includes 23 women who used both progestin-only and combined contraceptives before first pregnancy.
}

We found no clear association between duration of use of hormonal contraceptives before first pregnancy and pregnancy-related pelvic pain in the first pregnancy (Test for heterogeneity $p=0.23$ ). There was no evidence of a differential effect according to the hormonal content of the pill, i.e., progestin- only or combined estrogen-progestin pills (Test for heterogeneity $\mathrm{p}=0.94)$ (Table 4$)$.

We also performed an analysis classifying separately the 23 women that used both progestin-only and combined estrogen-progestin contraceptives. In this analysis the esti- 
mates were equal as those in the Table 4 for progestinonly and for combined estrogen-progestin contraceptives, and the estimate for women who used both was $\mathrm{OR}=2.0$ (95\% CI: 0.8-5.0). Finally, we excluded from the analysis these 23 women, and the results were not materially different than those shown in Table 4.

\section{Discussion}

In our study use of hormonal contraceptives was associated with the occurrence of pelvic pain in the first pregnancy, but not in the second and third pregnancies. Occurrence of pelvic pain in a previous pregnancy was strongly associated with occurrence of the symptoms in subsequent pregnancies.

During a fertile life, at least 20\% of women experience pelvic pain in at least one pregnancy. The prevalence of the symptoms increases with increasing parity $[2,9,12]$. Most of the published studies on determinants of pregnancyrelated pelvic pain originate from Scandinavia, where this condition appears to be prevalent $[2,3,9,10,13,18,19]$. Only a few studies have looked into hormonal contraceptives as a possible risk factor for pregnancy-related pelvic pain $[3,6,7,9,14]$. All these studies were negative or nonconclusive, and most of them were too small to allow any conclusions. None of them have stratified the analysis on parity, analysing each pregnancy separately. Our strategy of analysing each pregnancy separately might explain why our results deviate from earlier studies. If hormonal contraceptives are an explanatory biological factor in the development of pelvic pain, it might be an advantage to study each pregnancy separately, because of the high recurrence of the condition in subsequent pregnancies. Endresen [2] emphasises that both age and parity are important explanatory variables, out of which parity is the more powerful. She also argues that adjustment for age would hardly be required if the data were stratified for parity.

Östgaard et al. [11] reported that back problems independent of pregnancy was an important factor when predicting back pain and pain intensity in a future pregnancy. We did not have information about back pain before pregnancy in our study, and thus we could not take this factor into consideration in our analyses.

The response rate in this study was around 60\%, which might be considered low. The possible problems with a low response rate, such as selection bias, have been discussed elsewhere [20]. It is unlikely that the response rate introduced a selection bias that might cause major problems in this study. The unique person-number given to all Norwegian inhabitants made it possible for us to link a sub-sample of the women in the Norwegian Women and Cancer Study to the National Register of Education and
Fertility and compare the responses with the total invited group in the same sub-cohort. This linkage uncovered no selection bias except that the response rate increased with increased education. We have slightly better educated women in the cohort than expected according to the Norwegian female population as a whole [16]. In addition, no association between the proportion of women using hormonal contraceptives, parity or age at first birth was revealed according to the response rate from an earlier analysis within our same study cohort [21]. If ever users of hormonal contraceptives with pelvic pain were more likely to answer the questionnaire than never users of hormonal contraceptives without pelvic pain, selection bias could have occurred. We consider this to be rather unlikely, since a possible association between hormonal contraceptive use and pregnancy-related pelvic pain was not a known hypothesis in the general population at the time of the survey. Moreover, the questions about pregnancy-related pelvic pain were not mentioned in the study's letter of introduction or in the headings of the questionnaires used.

Differential misclassification of exposure [22] could have resulted in either an exaggerated or underestimated effect. However, we have no reason to believe that women with a history of pelvic pain systematically remembered their hormonal contraceptive use differently from women without this condition.

Our study could have been affected by recall bias: women might remember in more detail recent events (such as recent use of hormonal contraceptives or pain related to a recent pregnancy) compared to past events. Time elapsed since first birth is correlated with the woman's birth year, and we found a non-significant reduced risk of pregnancyrelated pelvic pain with increasing time elapsed since first birth. However, if pelvic pain incidence is increasing, younger women or women who gave birth for the first time close to enrolment will be more likely to report having suffered from the illness. Both the association between pelvic pain and women's birth year or age have been reported earlier [2,9].

\section{Conclusions}

Our results suggest that use of hormonal contraceptives before the first pregnancy may cause an increased risk of pregnancy-related pelvic pain in the first pregnancy. Pregnancy-related pelvic pain in a preceding pregnancy is a very strong predictor of pelvic pain in a subsequent pregnancy.

The association between use of hormonal contraceptives and pelvic pain in the first pregnancy is this study was weak, but it might be of interest in a public health perspective since both the prevalence of hormonal contracep- 
tive use before first pregnancy, and the prevalence of pelvic pain in pregnancy are high in Scandinavia.

\section{Competing interests}

None declared.

\section{Authors' contributions}

MK and EL conceived of the study and participated in its design and coordination. MK, EW and EL participated in the sequence alignment and drafted the manuscript. EA performed the statistical analysis. EW finalised the manuscript writing. All authors read and approved the final manuscript.

\section{Acknowledgements}

The study was supported by grants of the National Cancer Institute (CA 52449) and The Norwegian Cancer Society (9005). EW is supported by a grant from the Swedish Cancer Society.

\section{References}

I. Snelling FG: Relaxation of the pelvic symphyses during pregnancy and parturition. Am J Obstet I870, 2:56I-96.

2. Endresen EH: Pelvic pain and low back pain in pregnant women--an epidemiological study. Scand J Rheumatol 1995, 24:|35-|4|

3. Bjorklund K, Nordstrom ML, Odlind V: Combined oral contraceptives do not increase the risk of back and pelvic pain during pregnancy or after delivery. Acta Obstet Gynecol Scand 2000, 79:979-983.

4. Petersen LK, Hvidman L, Uldbjerg N: Normal serum relaxin in women with disabling pelvic pain during pregnancy. Gynecol Obstst Invest 1994, 38:21-23.

5. Albert H, Godskesen M, Westergaard JG, Chard T, Gunn L: Circulating levels of relaxin are normal in pregnant women with pelvic pain. Eur J Obstet Gynecol Reprod Biol 1997, 74:19-22.

6. Ostgaard HC, Andersson GBJ, Schultz AB, Miller JAA: Influence of some biomechanical factors on low-back pain in pregnancy. Spine 1993, I 8:61-65

7. Berg G, Hammar M, Moller Nielsen J, Linden U, Thorblad J: Low back pain during pregnancy. Obstet Gynecol 1988, 7 I:71-75.

8. Fung BK, Kwong CM, Ho ES: Low back pain of women during pregnancy in the mountainous district of central Taiwan. Chin Med J (Tapei) 1993, 51:103-106.

9. Ostgaard HC, Andersson GB, Karlsson K: Prevalence of back pain in pregnancy. Spine 1991, 16:549-552.

10. Kristiansson P, Svardsudd K, Von Schoultz B: Serum relaxin, symphyseal pain, and back pain during pregnancy. Am J Obstet Gynecol 1996, I 75: I 342-1347.

II. Ostgaard HC, Andersson GB: Previous back pain and risk of developing back pain in a future pregnancy. Spine 1991, 1 6:432-436.

I2. Mantle MJ, Greenwood RM, Currey HL: Backache in pregnancy. Rheumatol Rehabil 1977, 16:95-101.

13. Kogstad O, Biornstad N: [Pelvic girdle relaxation. Pathogenesis, etiology, definition, epidemiology]. Tidsskr Nor Laegeforen 1990, I 10:2209-22 II.

14. Kogstad O: [Pelvic instability. A controversial diagnosis]. Tidsskr Nor Laegeforen 1988, I 08: I I I 5-I I 19.

15. Noren L, Ostgaard S, Johansson G, Ostgaard HC: Lumbar back and posterior pelvic pain during pregnancy: a 3-year follow- up. Eur Spine J 2002, I I:267-27I.

16. Eiliv Lund, Merethe Kumle, Tonje Braaten, Anette Hjartaker, Kjersti Bakken, Elise Eggen, Torhild Gram Inger: External validity in a population-based national prospective study - the Norwegian Women and Cancer Study (NOWAC). Cancer Causes Control 2003.

17. Lunde AS, Lundeborg S, Lettenstrom GS, Thygesen L, Huebner J: The person-number systems of Sweden, Norway, Denmark, and Israel. Vital Health Stat 1980, 2: I-59.
18. MacLennan $\mathrm{AH}$ : The role of the hormone relaxin in human reproduction and pelvic girdle relaxation. Scand J Rheumatol Suppl 1991, 88:7-15.

19. Wergeland E, Strand K: Work pace control and pregnancy health in a population-based sample of employed women in Norway. Scand J Work Environ Health 1998, 24:206-2 I 2.

20. Kumle M, Weiderpass E, Braaten T, Persson I, Adami HO, Lund E: Use of Oral Contraceptives and Breast Cancer Risk: The Norwegian-Swedish Women's Lifestyle and Health Cohort Study. Cancer Epidemiology Biomarkers Prevention 2002, I I : | 375- I 38I.

21. Lund E, Gram IT: Response rate according to title and length of questionnaire. Scand J Soc Med 1998, 26:154-160.

22. Rothman K: Epidemiology: an introduction Oxford, Oxford University Press; 2002

\section{Pre-publication history}

The pre-publication history for this paper can be accessed here:

http://www.biomedcentral.com/1471-2393/4/11/prepub
Publish with Biomed Central and every scientist can read your work free of charge

"BioMed Central will be the most significant development for disseminating the results of biomedical research in our lifetime. "

Sir Paul Nurse, Cancer Research UK

Your research papers will be:

- available free of charge to the entire biomedical community

- peer reviewed and published immediately upon acceptance

- cited in PubMed and archived on PubMed Central

- yours - you keep the copyright

Submit your manuscript here:

http://www.biomedcentral.com/info/publishing_adv.asp
BioMedcentral 